Gender differences in sl eeping hours and recovery experi ence anong psychi atric nur ses i n Japan

\begin{tabular}{|l|l|}
\hline 著者 & $\begin{array}{l}\text { 大重 育美, NAKASH MA M t suyo, TOBI NA Takur o, } \\
\text { YAMAGUCH Tae, M NEMATSU Kazuo, TSUNAWAKE } \\
\text { Nor i aki }\end{array}$ \\
\hline $\begin{array}{l}\text { 大重 育美, 中島 充代, 飛奈 卓郎, 山口 多恵, 峰 } \\
\text { 松 和夫, 綱分憲明 }\end{array}$ \\
\hline $\begin{array}{l}\text { j our nal or } \\
\text { publ i cat i on ti tl e }\end{array}$ & GSTF Jour nal of Nur si ng and Heal th Car e \\
\hline vol une & 5 \\
\hline nunber & 1 \\
\hline page r ange & $190-193$ \\
\hline year & 2018 \\
\hline URL & ht t p: //i d. ni i . ac.j p/1127/00000713/ \\
\hline
\end{tabular}




\section{Gender Differences in Sleep Patterns of Shift Workers: Comparison of Sleeping Patterns before and after a 16-hour Shift of Psychiatric Nurses in Japan}

\author{
Narumi Ooshige \\ Professor, Japanese Red Cross Kyushu International \\ College of Nursing \\ Fukuoka, Japan
}

Mitsuyo Nakashima

Associate Professor, Faculty of Medicine, School of Nursing, Fukuoka University

Fukuoka, Japan

Takuro Tobina

Senior Lecturer, Faculty of Nursing and Nutrition, University of Nagasaki, Japan

Nagasaki, Japan

\begin{abstract}
In their attempts to balance sleep routines and their service schedules, nurses working in shifts are at a risk for developing sleep disorders. Therefore, the current study aimed to explore gender differences in sleeping patterns of psychiatric nurses from a 16-hour shift to two days off duty. It was found that male nurses went to bed late and that female nurses rose slightly early on the days they served night shifts. On an average, the sleeping hours of male nurses were about 2 hours longer than those of female nurses. After two consecutive days off duty, there was no difference in sleeping patterns of males and females. Before the night shift, females engaged in housekeeping and used short sleeping hours in rest time to compensate for the lack of sleep. Results highlighted the need for health management interventions for nurses working in shifts, considering gender differences.
\end{abstract}

Keywords-component; sleeping hours; night shift; gender differences; life activity; psychiatric nurses.

\section{INTRODUCTION}

The sleep cycle of a person working in shifts is often disrupted, as it is difficult to maintain the sleep-wake rhythm, given their service schedules; this makes them prone to developing sleep disorders [1] [2]. Although sleep is affected by various elements such as age, biological factors, environmental agents, and psychosocial factors, the secretion of a hormone in females causes the biggest difference in sleep patterns [3]. An adult female's sleeping hours are shorter than that of a male nurse, and a female nurse tends to be engaged in

\author{
Tae Yamaguchi \\ Senior Lecturer, Department of Nursing, Faculty of Nursing \\ and Nutrition, University of Nagasaki \\ Nagasaki, Japan
}

Kazuo Minematsu

Associate Professor, Department of School Health, Graduate School of Education, Nagasaki University, Japan. Department of Public Health, School of Medicine, Juntendo University, Japan

Nagasaki, Japan

Noriaki Tsunawake

Professor, Faculty of Nursing and Nutrition, University of Nagasaki, Fukuoka, Japan

housekeeping chores more than males, especially if they are in the early stages of their training. This could be a reason why they rise earlier than male nurses on an average [5]. Time spent in caring for the body differs across males and females, which may also be the reason for gender differences in the time of sleeping time.[4]. However, when it comes to nurses working in night shifts, research about gender differences in sleeping hours is lacking. Therefore, the current study is aimed at demonstrating how the difference in lifestyles of male nurses and female nurses affects their sleeping hours from a double shift service to their days off duty.

\section{MATERIALS AND METHOD}

\section{A. Participants}

Participants in the research included 26 nurses from the psychiatry specialty serving two shifts. There were 19 females with an average age of 37.9 years, and 7 males with an average age of 38.1 years. The male-female ratio of nurses in this study was similar to that found in most hospitals, with $42.4 \%$ nurses being males.

\section{Research Period}

The duration of the research was from October 2015 to March 2016.

\section{B. Instruments}

The study was conducted across six days, where participants were engaged in night shifts, and on two 
consecutive days, they were not on duty, as it was considered their day off. Physical activity (steps taken and energy expenditure) were measured using an accelerometer (Actimaker, Panasonic, Japan) during the phase of data collection, and it recorded the amount of body activities (number of steps) during the consultation period. The activity schedule (life activity) for the night shift and the days off duty included sleep, a meal, work, housework, conversation and social engagements, leisure, sports and a hobby, internet TV, video, and rest, and was considered as the statement of the unit for 15 minutes. Nurses could engage in life activities before night shift until 12:00 a.m., at which point their night shift began, and it ended at 04:00 p.m. In addition, the life activity of two consecutive day offs measured it as 24 hours until 12:00 a.m.

\section{Data analysis}

Data recorded included the participants' rising time during the two days off (day-offs), sleeping time, number of sleeping hours, time spent in each life activity, age, years of experience, whether they had children, commuting time, and number of work hours during the night shift. The data of male nurses and female nurses were compared using an unpaired t-test and chisquare test. To measure body activity, the number of steps was recorded, and it was compared across males and females. Furthermore, a repeated-measures two-way ANOVA was used to compare gender differences in sleeping hours across the night shifts and day offs. When a mutual action was significant, a simple main effect analysis was performed on transition in sleeping hours of males and females. The statistical software used was SPSS for Windows version 22 and the significance threshold level was set at .05.

\section{Ethical Considerations}

Using a document outlining the purpose and design of the research, the process was explained to the participant in charge of the medical institution, and consent was thus obtained.

In addition, this research was approved by the Japanese Red Cross Kyushu International College of Nursing research ethics screening committee (approval number 15-102).

\section{RESULTS}

\section{A. Participant demographics}

The average clinical experience was 13.5 years for female nurses and 15.7years for male nurses; however this difference was not significant. The average commuting time was 24.8 minutes for females and 37.1 minutes for males. The average naptime during a night shift was 83.6 minutes for females and 111.4 minutes for males. About $30 \%$ of the sample had children, and no significant difference was found between male nurses and female nurses, in this domain (Table 1).

\section{B. Comparison of sleeping time and sleeping hours}

It was found that male nurses went to bed late, as compared to female nurses, on both, the day offs and the days of the night shift. Female nurses rose earlier than male nurses
$(\mathrm{P}<.05)$. The number of sleeping hours of male nurses was longer than those of female nurses by about 2 hours on an average $(\mathrm{P}<.05)$. The gender differences were not significant in these areas: the sleeping time, rising time, and sleeping hours of the day offs (Table 2).

\section{Comparison of Body Activities (number of steps)}

In the night shift, female nurses worked twice as hard as male nurses. There were more male nurses during a night shift than female nurses, and the number of steps after a night shift was higher for male nurses. The first day-off had many male nurses, and there were many female nurses on the second day off (Table 3).

\section{Comparison of Life Action Time}

In life activities during the day-offs, a difference was found between male nurses and female nurses only before a night shift $(\mathrm{P}<.05)$. There was a difference between male nurses and female nurses in terms of the sleeping hours before a night shift, general housekeeping, and rest time; the number of hours was more for female nurses in sleeping and general housekeeping, and it was more for male nurses in rest time $(\mathrm{P}<.05)($ Table 4).

\section{E. Main effects}

A significant difference was seen only in the main effect of gender on the progress of sleeping hours as revealed by a twofactor analysis of variance (ANOVA). There was a main effect $(\mathrm{F}[1,23]=1.207, \mathrm{P}=\mathrm{n} . \mathrm{s}$. $)$ of progress of sleeping hours; $\mathrm{a}$ two-factor ANOVA was performed to explore gender differences and a mutual action $(\mathrm{F}[2,46]=4.28, \mathrm{P}<.05)$ (Figure. 1). There was no significant difference in the main effect; since there was a significant difference in the mutual action, a simple main effect analysis was performed. Results showed that for female nurses it was significant $(\mathrm{F}[2,46]=$ $8.06, \mathrm{P}<.05)$, and for male nurses, it was not $(\mathrm{F}[2,46]=$ $0.482, \mathrm{P}=$ n.s. $)$.

\section{DISCUSSION}

The male nurses in this study comprised of $27 \%$ of the whole sample, which is more than the ratio of male nurses in the country $(8.3 \%)$, as indicated by a national investigation. Moreover, since there were no significant gender differences in average age and years of clinical experience, age was considered to have little influence over this research.

The current study compared findings pertaining to sleeping hours before and after night shifts and life activities with 30year old people from the general population. The average sleeping hours for males in the general population were 8.4 hours on day-offs and 7.11 hours on weekdays[6]; the average sleeping hours for males in the current study were 8.3 hours (502 minutes) in the second day-off and 7.8 hours (468 minutes) on the first day-off and 10.3 (23 minutes) hours on the day of the night shift.

Similarly, for females in the general population, the average sleeping-hours were 7 hours on a weekday, 7.53 hours 
on a day off. For females of the current study, the average sleeping hours were 8.1 hours (490 minutes) on the day of the night shift, 7.9 hours (476 minutes) on the first day-off and 8.5 hours (517 minutes) on the second day-off. The sleeping hours of each female in the study were longer than their contemporaries in the general population. In a study with people working in double shifts [7], it was found that on an average, naps are taken for 1.85 hours (111 minutes), and the average number of sleeping hours after night shifts was 9.18 hours (550 minutes). Similar results were found for male nurses in the current study. In the current study, the number of sleeping hours during night shift days was longer for male nurses and shorter for female nurses than was found in previous studies [7]; this was also true of nap time hours. It is not concerned with the existence of acquisition for 120 minutes of naptime in the investigation for night shift's female nurses among 16 hours [8] .Regardless of the difference in naptime, there were no gender differences in fatigue before the night shift. However, after the night shift considerable difference was found in fatigue levels.

Since the female nurses of this research had less naptime than male nurses, it was expected that they would continue to experience fatigue. When the number of steps was compared, there was no gender difference, but, although male nurses had the sleeping hours shorter than female nurses before night shift, there were much number of steps at the time of night shift. The female nurses spent 202 minutes in general housekeeping, 51 minutes in life activities, and 6 minutes more in rest than males. In terms of life activities, even before their night shifts, female nurses engaged in work including housekeeping, as was also seen from previous studies [4] [5] and they believed that they would compensate for their short sleeping hours during their rest time.

On day offs, the sleeping hours of males in this study were longer by 5 hours than their contemporaries in the general population; this difference was not found among females. On the first day off, males spent 6 hours on the internet and with the TV [6]. The male nurses have spent much time for the work on the day off, it was assumed that there were several opportunities to carry out internet research, and so on.

Due to long service hours, nurses' sleeping hours become short easily. Moreover due to the nature of long hours of service and gender differences in shift work, the likelihood of experiencing intense fatigue becomes high, especially when

Table1Participantdemographics

\begin{tabular}{|c|c|c|c|}
\hline Category & Male(n=7) & Female $(n=19)$ & $\mathrm{P}$-value \\
\hline$\overline{\mathrm{Age}(\mathrm{SD})(\text { years })^{\mathrm{a}}}$ & $38.1(11.2)$ & $37.9(7.8)$ & 0.967 \\
\hline Clinical experience years as nurse (years) ${ }^{\mathrm{a}}$ & $15.7(13.5)$ & $13.5(7.4)$ & 0.705 \\
\hline Commuting time $(\mathrm{SD})(\mathrm{min})^{\mathrm{a}}$ & $37.1(27.6)$ & $24.8(17.3)$ & 0.185 \\
\hline Nap time(SD)(min $)^{\mathrm{a}}$ & $111.4(48.1)$ & $83.6(63.0)$ & 0.252 \\
\hline Having child $^{b}$ & $4(29 \%)$ & $10(71 \%)$ & \multirow{2}{*}{ טננ.ט ט } \\
\hline No having child ${ }^{\mathrm{b}}$ & $3(25 \%)$ & $9(75 \%)$ & \\
\hline
\end{tabular}

a: un-paired t test

b: Chi-test sleeping hours are short [9]. We investigated change in the degree of fatigue consciously experienced by medical-surgical female nurses during night shifts, and found the rate of drowsiness and the extent of eyestrain to be quite high [10]. Thus, for a nurse working in shifts, recovery from fatigue after a night shift is an important problem, and it is majorly associated with sleeping hours. It was found that time spent on sleep was 600 minutes or more than time spent on the internet, viewing TV, and in housework, and sleep can be secured before a night shift on the male nurse. On the day off after a night shift, the female nurse was spending much time in order of housework, the Internet, and TV except for sleeping hours. On the other hand, the male nurse had spent much time at work in order of the Internet and TV except for sleeping hours. On second day off, the female nurse had spent most time in housekeeping except for sleeping hours on the 2nd. This situation was the same in two consecutive day offs. Among male nurses, the work hours were increasing rapidly, followed by sleeping hours, and then by leisure time, and so on.

Even on the two consecutive day offs, males engaged in work. On the night shift day, females spent about 8 hours (490 minutes) in sleep, over 3 hours in general housekeeping, followed by time spent on the internet.

This study had several limitations. First, the limited sample size and small control group are associated with known risks of bias. Second, we were not able to measure fatigue depending on life activity. Therefore, a comparison of the fatigue by life activity contents was insufficient.

In conclusion, findings of the study highlight the importance of interventions designed for health management, considering gender differences among shift work nurses. Special attention towards life activity before the night shift is warranted.

\section{ACKNOWLEDGMENTS}

This research was supported by Grant-In-Aid for Scientific Research in Japan Society for the Promotion Science.

\section{Conflicts of interest}

The authors have no potential conflicts of interest that are relevant to this article.

\section{REFERENCES}

[1] K. Spiegelhalder, W. Regen, S. Nanovska, C. Baglioni, D. Riemann, "Comorbid sleep disorders in neuropsychiatric disorders across the life cycle," Curr Psychiatry Rep, 2013,15:364

[2] K. Kati, H. Mikko, S. Mikael, H. Christer, V.Jussi, K. Mika, P. Sampsa, "Job strain, sleep and alertness in shift working health care professionals $-\mathrm{A}$ field study," Industrial Health, 2013, Vol. 51, pp. 406-416.

[3] S. Miyazaki, N. Yamada, M. Ookawa, "Suimin gaku II," Kitaoojishobou (Kyoto), 86, 2011. (in Japanese)

[4] NHK Broadcasting Culture Research Institute : Japanese daily life time 2010- NHK Japanese daily life investigation, NHK Publishing Co. Ltd, 166, 2011 
Table2 Comparison of sleeping hours

\begin{tabular}{|c|c|c|c|}
\hline $\begin{array}{l}\text { Eveluation } \\
\text { point }\end{array}$ & $\operatorname{Male}(\mathrm{n}=7)$ & Female $(\mathrm{n}=19)$ & P-value \\
\hline sleeping time & 1:00 & $0: 23$ & 0.408 \\
\hline before night & 11:18 & $8: 28$ & 0.017 \\
\hline sleepinghours(SD)(min) & $623.9(54.0)$ & $490.1(101.4)$ & 0.003 \\
\hline sleepingtime & $1: 38$ & $0: 31$ & 0.317 \\
\hline 1st day off risingtime & 9:06 & 8:01 & 0.232 \\
\hline sleeping hours $(\mathrm{SD})(\mathrm{min})$ & $468.3(146.9)$ & $476.2(107.7)$ & 0.881 \\
\hline \multirow{3}{*}{$\begin{array}{l}\text { sleeping time } \\
\text { 2nd day off rising time } \\
\text { sleeping hours }(\mathrm{SD})(\mathrm{min})\end{array}$} & $0: 18$ & 0:03 & 0.771 \\
\hline & $8: 16$ & 8:09 & 0.916 \\
\hline & $502.4(166.1)$ & $517.3(138.2)$ & 0.821 \\
\hline
\end{tabular}

un-paired $t$ test

Table3 Comparison of the number of steps

\begin{tabular}{|c|c|c|c|c|c|}
\hline \multirow{2}{*}{ Eveluation point } & \multicolumn{2}{|c|}{ Male $(n=7)$} & \multicolumn{2}{|c|}{ Female $(n=19)$} & \multirow{2}{*}{ P-value } \\
\hline & Mean & $\mathrm{SD}$ & Mean & SD & \\
\hline day $\operatorname{shift}(10: 00-18: 00)$ & 9388.0 & 2340.0 & 7930.3 & 2705.8 & 0.248 \\
\hline before night shift $(0: 00-16: 00)$ & 1205.5 & 92.6 & 3975.1 & 1976.0 & 0.070 \\
\hline night $\operatorname{shift}(16: 00-10: 00)$ & 14449.4 & 1001.9 & 12984.6 & 3516.9 & 0.292 \\
\hline after night shuft(10:00-24:00) & 6198.0 & 4779.8 & 3837.9 & 2316.1 & 0.135 \\
\hline 1st day off(0:00-24:00) & 8120.5 & 5314.0 & 7032.6 & 3556.1 & 0.563 \\
\hline 2nd day off(0:00-24:00) & 5662.8 & 3798.7 & 7649.4 & 5289.3 & 0.332 \\
\hline
\end{tabular}

un-paired t test
[5] M. Tournai, S. Tournai. "Time study of nurses' shift work and the influence of domestic labor on fatigue after ordinary labor," 2004. Japanese Journal of Public Health 10: pp. 874-883. (in Japanese) [6][4] pp. $189-228$.

[7] S. Oriyama, Y.Miyakoshi, T. Kobayashi. "Ways of taking rest and breaks during night shifts for two-shift nurses and factors supporting work - A comparison of 12- and 16-hour night shifts," 2014. Japanese Society for Healthcare Administration; 21: pp. 21-31. (in Japanese) [8] S. Matumoto, T. Sasaki, M. Sakita. "The effects of the naps taken by hospital nurses in 16-hour nightshifts on their subjective fatigue feelings and subsequent sleep," 2008. Journal Science of Labour 84 (1), pp. 25-29, 2008. (in Japanese)

[9][3], pp. 134-135.

[10] Kazuo Minematsu, Tae Yamaguchi Mitsuyo Nakashima Noriaki Tsunawake, Nsrumi Ooshige: "Health Management for Medical-Surgical Female Nurses Having Night Shift Working." 2017; International Journal of Nursing \& Clinical Practices, 4, pp. 1-5.

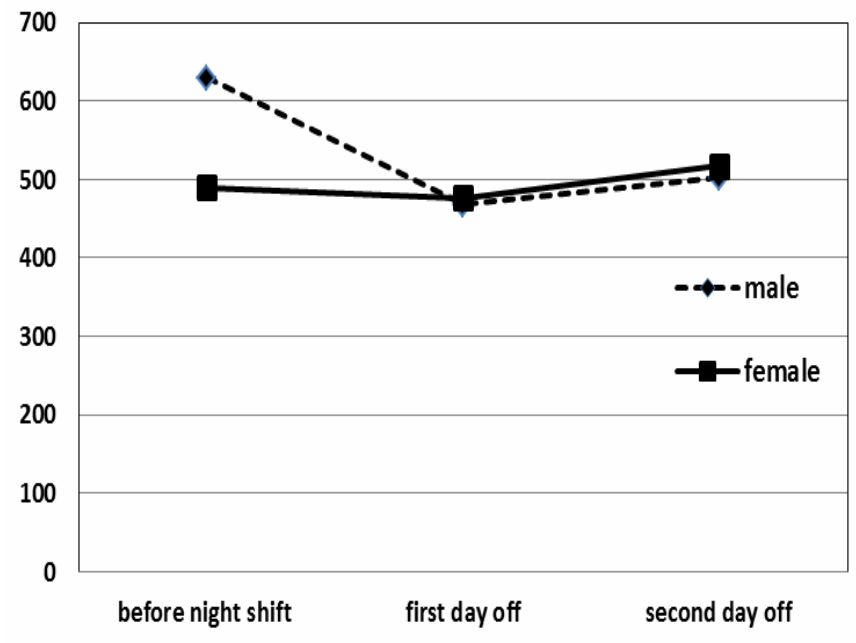

Figure1 Transition of the sleeping hours according to sex

Table 4 Comparison oflifeactivity(min)

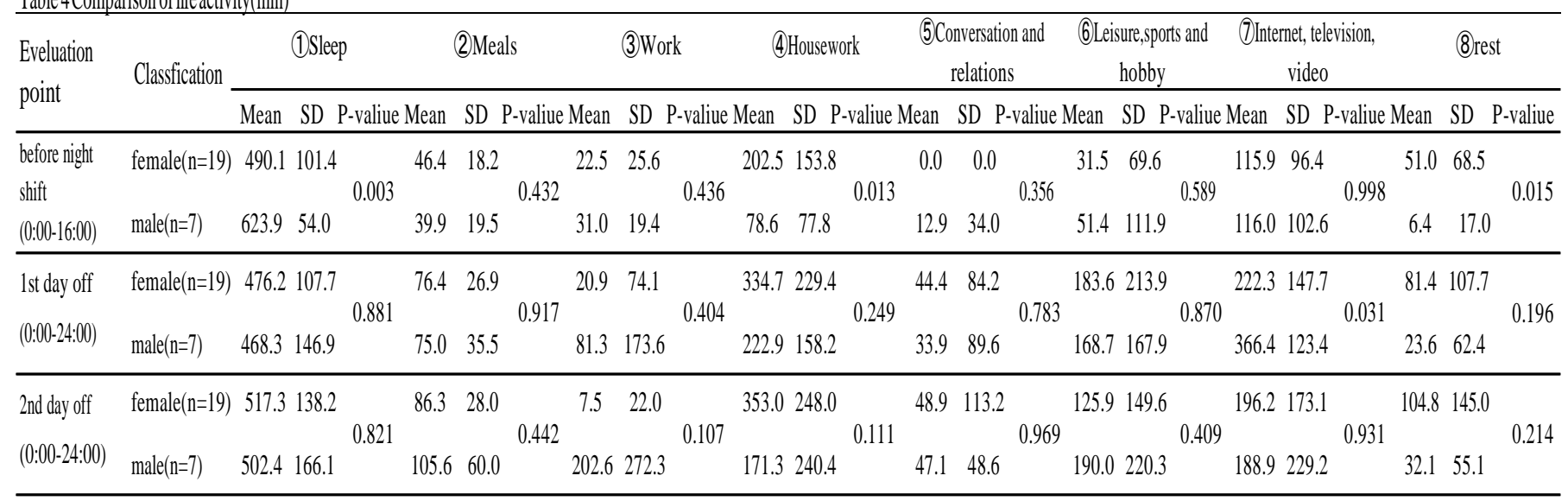

un-paired t test 